Recebido: 20/06/2016

Aprovado: 25/07/2016

\title{
Promessas de futuro na brecha do tempo: \\ O momento constitucional brasileiro de 1987/1988 como produtor de um regime próprio de historicidade
}

Eduardo Ubaldo Barbosa*

Resumo: Neste artigo, com apoio nas formulações teóricas de François Hartog e Reinhart Koselleck, defende-se a hipótese de que a Assembleia Nacional Constituinte (ANC) de 1987/1988 produziu um regime de historicidade próprio, isto é, uma maneira idiossincrática de articulação das categorias do passado, do presente e do futuro em uma disputa narrativa que deixou sua marca na Constituição promulgada em 5 de outubro de 1988. Assim, o debate constituinte de 1987/1988 passa a ser encarado como uma disputa pela construção de uma narrativa situada em um presente marcado pela recusa ao passado e pelo signo da imprevisibilidade, mas igualmente voltado à construção da narrativa de futuro por intermédio da promulgação de um novo texto constitucional. Tomando como exemplo e aporte explicativo a formação do autodenominado "Centro Democrático", ou "Centrão", alcançou-se a conclusão de que o resultado desse processo foi a promulgação de uma Constituição prenha da noção de "futuro" e de "promessas" a serem (ou não) realizadas a posteriori.

Palavras-chave: Assembleia Nacional Constituinte; Constituição Federal de 1988; Centrão.

\begin{abstract}
This paper, supported by the theoretical formulations of François Hartog and Reinhart Koselleck, posits that the Brazilian National Constituent Assembly (1987/1988) produced an idiosyncratic way of articulate the past, the present, and the future categories in a narrative dispute that has left its signature on the Constitution promulgated on 1988 October 5th. Thus, the constitutional debate that marks the end of the military regime in Brazil shall be regarded as a dispute over the construction of a narrative located in a "suspended present" represented by the construction of the future through the promulgation of a new Constitution filled with future promises, and taking as example the formation of self-styled "Centro Democrático", or "Centrão".
\end{abstract}

Keywords: Brazilian National Constituent Assembly; 1988 Federal Constitution; "Centrão".

\footnotetext{
* Mestrando em Direito, Estado e Constituição pelo Programa de Pós-Graduação da Faculdade de Direito da Universidade de Brasília (UnB). Bacharel em História pela UnB e em Direito pelo Centro Universitário de Brasília (UniCEUB).
} 


\section{Introdução}

Atento à crescente preocupação acadêmica de contribuir com a necessária construção de um diálogo metodológico entre a historiografia e a história do direito, particularmente do direito constitucional brasileiro, este breve artigo se preocupará em suscitar questionamentos a propósito do momento constitucional representado pela Assembleia Nacional Constituinte (ANC) de 1987/1988 a partir da ideia de que ela produziu um regime de historicidade próprio, isto é, uma maneira idiossincrática de articulação das categorias do passado, do presente e do futuro em uma disputa narrativa que, a toda evidência, deixou sua marca na Carta Constitucional promulgada em 5 de Outubro de 1988. Em apertada síntese, o artigo buscará oferecer aos seus leitores aproximações para que se compreenda o espaço discursivo da ANC de 1987/1988 como um locus privilegiado no qual os mais diversos atores sociais formularam "promessas" de futuro, o que permitiria enxergar a ANC como um "presente político" no qual o próprio tempo (rectius: a percepção que os atores cultivavam deste) restara suspenso em um momento de transição marcado pelo signo da imprevisibilidade. Com o aporte teórico de noções como a de "tempo histórico" e de "regime de historicidade", elaboradas, respectivamente, pelos historiadores Reinhart Koselleck e François Hartog, testa-se a hipótese de que essa "brecha temporal" representada pelos trabalhos e debates da ANC - ela mesmo força produtora de uma temporalidade específica - teria resultado na promulgação de uma Constituição prenha da noção de "futuro" e de "promessas" - a serem (ou não) realizadas $a$ posteriori.

\section{"Uma cacofonia de vozes e interesses": as forças políticas e atores sociais na Assembleia Nacional Constituinte (ANC)}

Ao analisar as condições históricas que tornaram possível a reunião da Assembleia Nacional Constituinte (ANC) de 1987/1988, bem como as consequências desse processo sobre o próprio sentido que a elaboração da Carta Constitucional acabou por adquirir aos olhos dos brasileiros, Leonardo Augusto de Andrade Barbosa observa que "as forças políticas envolvidas no processo constituinte se jogaram nele sem nenhuma certeza sobre como 'aquilo' iria acabar" (BARBOSA, 2012:147). Em suas palavras, "não havia um projeto oficial a ser traduzido pela Constituição", mas, antes, “diversos projetos políticos e ideológicos fragmentários a articular, mediados por uma forte exigência de cidadania, entendida 
principalmente como direito à participação ativa na via política do país" (BARBOSA, 2012:147).

Em síntese, Barbosa identifica o "ineditismo" e o "caráter verdadeiramente revolucionário" da Constituição de 1988 justamente naquilo que denomina "uma forma nova de perceber o direito, em especial o direito constitucional”. Se, antes, ao longo da história constitucional brasileira, a atividade afeta à elaboração de uma Constituição representaria uma tarefa eminentemente técnica e, como tal, restrita a um restrito grupo qualificado de "notáveis" ("elitismo constitucional"); noutro giro, a experiência do biênio 1987/1988 teria rompido com esse "paradigma de processo constituinte", eis que, ainda segundo Barbosa, "o pronunciamento de povo soberano não seria [mais] encarnado pelo uníssono da voz autoritária, chancelada pelo verniz bacharelesco, mas por uma autêntica polifonia, cujo sentido somente pode ser apreendido em movimento, em seu próprio fazer" (BARBOSA, 2012:147).

No mesmo sentido, o historiador Daniel Aarão Reis Filho escreve que, quando da instalação da ANC em $1^{\circ}$ de fevereiro de 1987, "havia, em quase toda a nação e entre os parlamentares, uma certa euforia com o desenlace dos acontecimentos, considerados positivos para a construção de uma nova ordem democrática" (AARÃO REIS FILHO, 2014:152). Não obstante, em que pese terem sido "poucas e indistintas as vozes que mantinham questionamentos quanto à validade e à legitimidade daquela Assembleia", Daniel Aarão Reis Filho observa que se revelaram múltiplas as maneiras pelas quais os representantes dos mais diversos grupos da sociedade civil enxergavam a construção do novo texto constitucional. Assim,

o Congresso tornara-se objeto de pressões e contrapressões em que se disputavam os votos dos parlamentares. Segundo o presidente da Assembleia, citando dados de sua secretaria, cerca de 10 mil pessoas, diariamente, percorriam corredores e salas lutando por seus interesses, assediando, persuadindo, barganhando, cabalando votos. Havia ali "de um tudo": grupos de pressão (os chamados lobbies) de distinta natureza, agindo em nome dos trabalhadores e das grandes corporações privadas, nacionais e estrangeiras; representantes das agências estatais, de funcionários civis e militares; de organizações femininas e estudantis; de entidades de defesa do meio ambiente e das nações indígenas. Sem contar as mobilizações populares, fora e dentro do Congresso, em favor das respectivas demandas. Nas galerias, acompanhando de perto discursos e votações com vaias e aplausos, ou acampando nos gramados adjacentes às duas Casas do Congresso Nacional, em Brasília, milhares de pessoas acompanhavam, mesmo que indiretamente, a elaboração da Constituição. (AARÃO REIS FILHO, 2014:158).

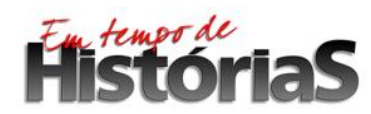


Não por acaso, Aarão Reis Filho se vale da sugestiva expressão "cacofonia de vozes e interesses" (AARÃO REIS FILHO, 2014:153) para designar a multiplicidade de atores sociais que, de alguma forma, se fizeram presentes no "momento constitucional" de 1987/1988, seja no âmbito institucionalizado da própria ANC, seja sob a forma de pressão externa a interagir com o establishment congressual, amoldando as diretrizes de atuação dos partidos e parlamentares constituintes aos seus interesses particulares. Assim, não se afigura equivocado afirmar que, desde o final dos anos 1970, um progressivo e gradual consenso a respeito da necessidade da promulgação de uma Carta Constitucional garantidora de direitos e liberdades em contraposição ao regime de exceção iniciado no ano de 1964, entendido como o "entulho autoritário" a ser extirpado, foi sendo forjado no seio da classe política e da sociedade civil brasileira, especialmente após a intensificação da luta pela anistia, ao final da década de 1970, e das manifestações pelo reestabelecimento das eleições diretas, já em meados da década de $1980 .^{1}$

No entanto, igualmente correta se mostra a assertiva de que, em que pese o relativo consenso sobre a necessidade de uma Constituinte ${ }^{2}$, é impossível não identificar a existência de discursos constitucionais distintos em confronto no seio da ANC de 1987/1988, cada qual procurando impor seus interesses e suas visões sobre o que deveria estar albergado no texto constitucional, o que, ao fim e ao cabo, aponta para a coexistência de projetos de futuro díspares, dotando este "presente político" da Constituinte de um regime de historicidade próprio a ser investigado.

\section{A existência de um regime de historicidade próprio da Assembleia Nacional Constituinte de 1987/1988: uma "brecha” temporal em um período de transição.}

\footnotetext{
${ }^{1}$ Segundo Leonardo Barbosa, em que pese a ideia de convocação de uma ANC já tenha sido formalizada em 1971 com a Carta do Recife do MDB, esta permaneceu restrita até 1977, com a promulgação do Pacote de Abril, momento a partir do qual "a ficção de normalidade político- institucional armada pelo governo esgarçou-se definitivamente" com a "intensificação do movimento pró-constituinte nesse período". Posteriormente, ainda segundo Barbosa, entre 1977 e 1985, o movimento em prol da ANC progressivamente escapou dos círculos político-partidários formalizados, atingindo importantes instituições e movimentos populares: "Não há como falar do processo histórico que culminou com a Convocação da Constituinte de 1987/1988 sem mencionar outros dois movimentos que, desde o primeiro instante, estiveram presentes no debate sobre a nova Constituição Brasileira e, de certa forma, mesclaram-se a ele: a luta pela anistia e as manifestações pelo restabelecimento das eleições diretas. Ambos demonstraram uma capacidade de mobilização popular superior até à do próprio movimento pró-constituinte" (BARBOSA, 2012:174).

${ }^{2}$ Muito embora a defesa de uma Assembleia exclusiva não tenha prosperado, prevalecendo a fórmula do Congresso com poderes constituintes com a promulgação da EC n. 26, de 27 de novembro de 1985.
}

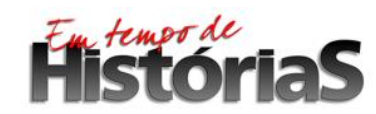


Tal qual arquitetada pelo historiador François Hartog, a noção de "regime de historicidade" revela-se operativa e fornece caminhos interpretativos não convencionais à análise do processo da ANC de 1987/1988, a partir do estudo da maneira pela qual os atores históricos entendiam a relação do processo constituinte com o próprio tempo, emprestandolhe sentidos particulares e expectativas de futuro igualmente distintas. Segundo F. Hartog, a noção de regime de historicidade não é uma realidade dada, mas é, antes, uma categoria formal a ser construída pelo historiador que se aproxima do tipo-ideal weberiano, consubstanciando-se em "uma maneira de engrenar passado, presente e futuro", expressando "a forma da condição histórica, a maneira como um indivíduo ou uma coletividade se instaura e se desenvolve no tempo" (HARTOG, 2013:12).

Igualmente operatória se mostra a noção de "tempo histórico" construída por Reinhart Koselleck, segundo quem este "tempo histórico" - que, diga-se, não se confunde com o tempo cronológico - seria produzido pela distância (tensão) criada entre o "espaço de experiência" e o "horizonte de expectativa" nos quais se inserem agentes históricos em determinado contexto, oferecendo, assim, uma "chave para mostrar o tempo histórico em mutação". (KOSELLECK, 2006:322) Para os fins deste breve artigo, vale observar que, para R. Koselleck, desde o último quartel do século XVIII, um processo de "temporalização das histórias" teria tido lugar no seio da civilização ocidental, de modo que o conceito moderno de "História", no singular maiúsculo, concebido como uma entidade en soi même, de natureza teleológica e (quase) metafísica, modificou inclusive a compreensão que temos do próprio tempo. Não por acaso, F. Hartog, com apoio nas lições já clássicas de R. Koselleck, bem observa que, "desde então, o tempo não é mais somente o quadro do que acontece; as coisas não se dão mais no tempo, mas pelo tempo: ele se transforma em ator", de modo que "é da tensão entre a experiência e a expectativa que resulta propriamente o tempo histórico" (HARTOG, 2013:4). Assim, de acordo com R. Koselleck, no Antigo Regime, voltava-se para o passado a fim de compreender o que acontecia no presente e, ato contínuo, aconteceria no futuro (historia magistra vitae). Já no regime moderno, contrario sensu, é a categoria do futuro - entendida como o farol luminoso que torna o presente compreensível - que assume papel de destaque na ribalta da compreensão do tempo histórico.

Nesse ambiente, entendendo-se o momento constitucional de 1987-1988 como dotado de um regime de historicidade próprio, poder-se-ia afirmar que, durante a ANC, o próprio "presente" - confrontado, de um lado, por um "passado" que, malgrado necessitasse ser enterrado, insistia em não passar, e, de outro, por um "futuro" incerto a ser construído a partir 
de decisões políticas fundamentais a ser tomadas no "aqui e agora" - restou suspenso em meio às incertezas quanto ao porvir, fazendo da Assembleia Nacional Constituinte um locus privilegiado de articulação de passado, presente e futuro? Ora, cuida-se de hipótese que não deveria ser descartada prontamente, sendo este breve artigo uma aproximação à elaboração de uma possível resposta a esse questionamento.

Inicialmente, no que tange à categoria meta-histórica referente ao "passado", não é tarefa das mais difíceis identificar o repúdio ao passado (amplamente identificado com a ordem constitucional autoritária anterior) nos discursos dos principais atores da ANC, mesmo entre aqueles abrigados mais à direita no espectro político-ideológico nacional. Nas palavras de José Theodoro Mascarenhas Menck, "a tese de uma nova Constituição estava intimamente vinculada à ideia de superar o regime militar" (MENCK, 2008:21). Nesse sentido, ainda segundo Menck, “diversos parlamentares, dos mais diversos partidos, reclamarão, ao longo das primeiras sessões, contra a usurpação dos poderes do Poder Legislativo e, de forma geral, contra a legislação oriunda do período militar, que ficaria, posteriormente, conhecida como "entulho autoritário"” (MENCK, 2008:21).

De fato, a rejeição à ordem constitucional anterior pautou boa parte dos principais discursos proferidos da tribuna do Congresso Nacional, conforme se verifica da leitura do pronunciamento feito por Ulysses Guimarães, em 3 de fevereiro de 1987, um dia após a sua eleição para a Presidência da Assembleia:

Srs. Constituintes, esta Assembleia reúne-se sob um mandato imperativo: o de promover a grande mudança exigida pelo nosso povo. (Palmas). Ecoam nesta sala as reivindicações das ruas. A Nação quer mudar, a Nação deve mudar, a Nação vai mudar. [...] O Brasil não cabe mais nos limites históricos que os exploradores de sempre querem impor. Nosso povo cresceu, assumiu o seu destino, juntou-se em multidões, reclamou a restauração democrática, a justiça social e a dignidade do Estado.

Igualmente, no discurso de promulgação da assim denominada "Constituição Cidadã", em 5 de outubro de 1988, o Presidente Ulysses Guimarães não se furtou a proclamar o "nojo" e o "ódio" nutrido com relação ao passado autoritário que precedera à ANC, fortalecendo a clássica tentativa retórica de realizar um corte histórico no tempo, mostrando que o presente veio expurgar os erros do passado. ${ }^{3}$ Assim, em que pese não se desconheça a "estratégia de

\footnotetext{
${ }^{3}$ Possivelmente, o mais notável dos exemplos acerca da necessidade de rejeição do passado em momentos de rupturas históricas tenha se dado com a Revolução Francesa, quando, ainda em 1789, optaram os revolucionários
} 
liberalização política implementada pelas presidências dos generais Ernesto Geisel (1974-79) e João Figueiredo (1979-85)" por meio da qual "os detentores do poder puderam liberalizar gradualmente e sob controle o regime autoritário e institucionalizar uma democracia 'forte', na qual os militares mantivessem um direito de veto sobre a vida política do país" (ARTURI, 2001:11), o fato é que, ao menos na retórica utilizada na locus discursivo da ANC, o passado ditatorial deveria ser afastado, eis que incompatível com a nova ordem constitucional a ser implantada.

A categoria do presente, por sua vez, revelava-se, em certa medida, incompreensível, o que, via de consequência, enevoava projeções confiáveis de futuro - o que não deixa de ser comum aos períodos tidos como "de transição". Interessante, neste particular, a apropriação realizada por François Hartog da noção de "brecha (gap) entre o passado o futuro (between past and future)" construída por Hannah Arendt para se compreender esta espécie de "estranho estremeio no tempo histórico, onde se toma consciência de um intervalo no tempo inteiramente determinado por coisas que não são mais e por coisas que ainda não são" (apud Hartog, 2013:22). Em suma, esse "presente perpétuo" seria um período suspenso, no qual, procurando enterrar um passado e construir um futuro, os atores careceriam de uma base sólida sob a qual poderiam andar, de modo que, sem referências seguras no passado “inventando tradições”, inclusive, se necessário - tudo poderia ocorrer.

Some-se a essa circunstância, o fato de que, nas palavras de Gilberto Bercovici, o poder constituinte "não tem forma predeterminada de manifestação e carece de limites jurídicos", mesmo porque, "se os tivesse, não poderia criar uma nova ordem, mas se moveria no marco da ordem preexistente, não seria constituinte, seria constituído" (BERCOVICI, 2013:309). Isso apenas contribui para se alcançar a conclusão de que, neste "presente suspenso", narrativas e projeções de futuro encontram-se em gestação sem que seja possível saber, de antemão, os contornos que desenvolverão a posteriori. Nesse sentido, o constitucionalista português J. J. Gomes Canotilho leciona, com apoio nas já mencionadas categorias propedêuticas elaboradas por R. Koselleck, que várias são as "instâncias de temporalidade" a serem convocadas visando a construção de uma "teoria da Constituição temporalmente adequada":

franceses pela rejeição radical do passado, recusando, sob o vago rótulo de "Ancien Régime" tudo aquilo que a precedeu. (cf. BARBOSA, 2015). 
Em primeiro lugar, qualquer constituição é o "presente do passado", pois não deixa de ser "memória na história" mesmo quando propõe rupturas (revolucionárias ou não) com o seu passado. Em segundo lugar, é o "presente do presente", pois ela dedica sempre uma indispensável atentio à conformação da ordem jurídica actual. Pretende ser - nalguns casos, como veremos, de forma utópico-programática -, o "presente do futuro" ao proclamar tarefas e fins para o futuro, mas, sobretudo, ao antecipar expectativas de se converter em lei para as gerações futuras. Neste sentido, a teoria da Constituição tanto localiza lugares filosóficos de esperança ("horizonte de expectativa") como insiste nos lugares de experiência ("espaço de experiência"). (CANOTILHO, 2006:26).

Trabalhando a partir da realidade constituinte brasileira de 1987/1988, Stéphane Monclaire observa com precisão que a redação de uma nova Constituição significava mais do que "apenas" a alteração da ordem jurídica em vigor, mas também trazia em seu bojo a possibilidade de "oferecer a tais ou quais grupos sociais (que os políticos diziam representar) alguns dos bens jurídicos e simbólicos por eles reclamados e, dessa maneira, permitir o fortalecimento da imagem dos representantes, dos laços entre representantes e representados e do princípio de representação" (MONCLAIRE, no prelo:7). Assim, afigura-se plenamente possível ventilar a hipótese de que a ANC se tornou uma arena privilegiada de embates pelo poder de construir um discurso para o futuro, de modo que, mais do que apenas o retrato das "forças reais de poder" existentes em determinada conjuntura social (cf. LASSALLE: 2014), a Constituição também teria passado a representar o projeto de futuro para a Nação em construção. Não por acaso, no já mencionado discurso de Ulysses Guimarães, em 3 de fevereiro de 1987, a referência ao porvir dá o tom do pronunciamento, no bojo do qual se encontra a sentença de que "a Constituição deve ser - e será - o instrumento jurídico para o exercício da liberdade e da plena realização do homem brasileiro".

Nesse sentido, precisa é a observação de J. Menck de que o discurso voltado ao futuro é a tônica nos trabalhos da ANC, eis que esta passou a visar "a uma atuação de longo prazo, pois implicava atacar um amplíssimo leque de necessidades sociais", o que "não caberia nos estreitos limites de uma carta constitucional que visasse apenas organizar os poderes do Estado e dar as linhas mestras da organização social e econômica da sociedade, como prescrevia a doutrina jurídica clássica" (MENCK, 2008:26). Assim, com base no aporte teórico de tais aproximações, não se afigura absurda a hipótese de que os debates, as manobras e as votações da ANC podem ser entendidos como um momentum de disputa entre os representantes de grupos de interesses da sociedade civil, em um determinado tempo histórico, pelo controle da elaboração de um projeto de futuro a partir de uma negação, ao 
menos retórica, do passado ("entulho autoritário"). Por sua vez, acabou-se por dotar o momento constituinte de 1987/1988 de uma temporalidade própria, caracterizada pela existência de um presente suspenso e incerto, como, aliás, sói ocorrer em momentos de transição de regimes de exceção aos períodos de normalidade democrática. É dizer, uma disputa pelo poder de controlar a narrativa de futuro da vida política e social do país ao decidir quais direitos, prerrogativas e instituições (no sentido mais amplo do termo) encontrariam abrigo no texto constitucional, protegendo-os do ímpeto reformista de futuras maiorias parlamentares efêmeras, impondo constrangimentos ao poder constituinte derivado (cf. WALDRON, 2001).

\section{Da formação do "Centro Democrático", ou "Centrão", no bojo da Assembleia Nacional Constituinte de 1987/1988}

Ilustremos o quanto exposto tomando por auxílio exemplificativo a formação e institucionalização do assim denominado "Centro Democrático", ou "Centrão", uma vez que se trata de um dos mais bem-acabados exemplos desta disputa de interesses e horizontes de expectativas distintos quanto ao novo regime constitucional (e de historicidade, por suposto) a ser inaugurado com a promulgação do texto construído a partir dos debates e votações da ANC (cf. FREITAS, MOURA, MEDEIROS, 2009). O autodenominado "Centrão" consubstanciava-se em um conglomerado de 290 parlamentares constituintes, majoritariamente conservadores, provenientes das bancadas do PMDB, do PFL, do PDS, do PTB, do PL, do PDC e, ainda que minoritariamente, do próprio PDT, tendo por lideranças principais os parlamentares José Bonifácio de Andrada (PDS), Expedito Machado (PMDB), Ricardo Fiúza (PFL), Gastone Righi (PTB) e Roberto Cardoso Alves (PMDB).

Em apertada síntese, tratou-se de uma tentativa, em grande medida exitosa, de exercer, com o apoio ostensivo de grande parte da mídia nacional, um efetivo controle dos possíveis horizontes a serem abertos pelo processo constituinte, especialmente no que diz respeito à extensão dos direitos trabalhistas, à política da reforma agrária e à organização do sistema financeiro - a par de fornecer apoio ao Presidente da República, José Sarney (PMDB). Com efeito, este grupo suprapartidário com perfil de centro-direita - formado ao final do primeiro ano de trabalhos da ANC - foi, para o que interessa mais diretamente a hipótese ventilada no presente artigo, "responsável pela reviravolta no processo de elaboração constitucional ao 
conseguir alterar, por meio de um projeto de resolução, as normas regimentais que organizavam os trabalhos constituintes" (ABREU, 2001:1304).

Nesse particular, interessante observar, com o aporte de Jon Elster a partir de sua análise das experiências constituintes paradigmáticas da Filadélfia e de Paris, a relevância das normas procedimentais internas de debates e votações no bojo das Assembleias Constituintes ("internal procedures rules"), bem como de sua influência na elaboração de seus produtos finais:

Another aspect of the constitution of the constituent assembly concerns its internal procedures rules (...) The effect of such procedural rules can be profound for three reasons. First, as we know from social choice theory, the process of aggregating given preferences into a final decision is deeply affected by the rules of the assembly, depending on the incentives they create for tactical voting. Third, the setting of the debates may affect those preferences themselves, depending on the scope that is allowed for argument and persuasion as distinct from mere voting and bargaining. In sum, procedure affects the transformation, expression, and aggregation of preferences in ways that can be crucial to the final outcome (ELSTER, 1994, p. 74).

No caso da ANC, a organização dos trabalhos constituintes deitou efeitos importantes no próprio desenrolar de seus trabalhos, especialmente no que diz respeito aos trabalhos da Comissão de Sistematização (composta pelos relatores das subcomissões e comissões, dos presidentes das comissões e de 49 outros membros da $\mathrm{ANC})^{4}$, por meio da qual, em apertada síntese, o seu presidente entregaria ao relator eleito a missão de conjugar os oito anteprojetos recebidos em um projeto de texto a ser debatido e encaminhado ao plenário que, após emendas e votações, resultaria em um sucessão de projetos até a aprovação do texto final - o que evidência a importância de tal Comissão de Sistematização e, pois, do texto nela elaborado e aprovado.

Ocorre, porém, que "com a vitória de [Mário] Covas [à presidência da Comissão de Sistematização], e sua preferência por relatores com perfil de centro-esquerda, a reação a essa

\footnotetext{
${ }^{4}$ Os trabalhos da ANC foram instalados em primeiro de fevereiro de 1987, sob a presidência de Ulysses Guimarães e tendo o deputado Bernardo Cabral como o relator geral. Como sói acontecer em processos constituintes, a organização dos trabalhos obedeceu a determinados procedimentos para viabilizar todo o processo, como a criação de comissões gerais (num total de oito), subcomissões (24 ao todo), uma comissão de redação e uma de sistematização - além, é claro, do plenário da Constituinte onde seria votado todo o projeto de Constituição. A comissão de sistematização seria encarregada de organizar e dar coerência ao projeto - o que representou uma enorme concentração de poderes nas mãos dos constituintes que a comandaram (cf. FREITAS, MOURA, MEDEIROS, 2009:10/11).
} 
sistemática tornar-se-ia cada vez mais forte, principalmente nas subcomissões e comissões em que o plenário reagiu aos anteprojetos propostos":

O núcleo governista soube capitalizar as insatisfações dos constituintes que não tinham assento na Sistematização. Esse processo, inerente à própria lógica da organização dos trabalhos, manifestava-se como um conflito entre plenário e comissão. $\mathrm{O}$ instrumento adequado para mudar as regras do jogo era a apresentação de projetos de resolução, os quais, para sua tramitação, demandavam a assinatura da maioria absoluta dos constituintes. Para angariar apoio, foram enfatizadas justamente as duas demandas principais: o direito de os parlamentares apresentarem novas emendas - maior participação do plenário; e a criação de um dispositivo que contornasse a condição preferencial do projeto de Sistematização. [...] Os líderes desse processo habilmente elaboraram um projeto de resolução no qual se destacavam dois dispositivos. Um permitia a elaboração de emendas coletivas, as quais, pelo número de subscrições, poderiam ter preferência automática sobre o projeto da Sistematização. O outro criava o destaque para a votação em separado (DVS). Pelo DVS, a aprovação de um requerimento impunha, a quem quisesse manter no texto a parte destacada de um projeto antes aprovado, o ônus de conseguir o quórum de maioria absoluta. Em outros termos, um dispositivo do projeto da Sistematização, destacado para votação em separado, precisaria obter 280 votos em plenário para permanecer no texto (DHBB, 2001:1305).

Não por acaso, Daniel Aarão Reis observa que "o objetivo principal a curto prazo [do "Centrão"] era reformular o regimento interno, o que ensejaria a derrubada da engenharia elaborada por Mário Covas", bem como "a reabertura, considerada estratégica, da questão relativa à metodologia dos debates" (AARÃO REIS FILHO, 2014:159). Com efeito, o principal argumento veiculado pelo "Centrão" para justificar sua atuação era justamente o de que havia, no seio da ANC, uma "tirania das minorias", que desejavam aprovar suas propostas sem qualquer poder de atuação da maioria do plenário (MUNHOZ, 2011:358). Dito na linguagem própria e particular da ciência política, o que estava em jogo era o poder de controlar, dentro do possível, a definição da agenda constituinte (agenda setting), dentro da qual se encontra a possibilidade de ditar o ritmo e o tom dos debates da ANC, "acelerando" o tempo dos debates e votações que interessassem e, noutro giro, "refreando" os projetos em sentido contrário, moldando as atividades e expectativas de futuro advindas da ANC conforme os interesses do grupo detentor do poder de regular a "questão relativa à metodologia dos debates". Nesse passo, impossível ignorar outrossim a "maior proximidade entre a cúpula do Centrão e o Planalto, ou seja, acesso a verbas e a cargos", de modo que "as vitórias mais contundentes do Centrão em plenário foram aquelas em que o grupo agiu

\section{Hitstorias}


coordenando, junto aos agentes interessados, os recursos por estes tornados disponíveis para arregimentar o apoio dos parlamentares" (ABREU, 2001:1306).

Possivelmente, o exemplo mais simbólico desta disputa tenha sido a vitória do "Centrão" no tratamento dado ao direito à propriedade, especialmente com relação às disposições relativas à reforma agrária - quando, mesmo minoritário, o "Centrão" pôde evitar a obtenção da maioria absoluta dos que pretendiam emendar o texto originalmente proposto.

Nesse sentido,

ao excluir a hipótese de desapropriação de terras produtivas, a nova Constituição significou uma regressão com relação ao Estatuto da Terra que Castelo Branco fizera o Congresso aprovar em 1965. Em outras questões, igualmente - com a posse e o uso do solo urbano, o sistema financeiro, a reforma do Judiciário e do direito tributário -, as propostas reformistas foram vencidas pelo rolo compressor das direitas, vertebradas pelo “Centrão". (AARÃO REIS FILHO, 2014, p. 164)

Noutro giro, porém, faz-se necessário e importante pontuar que também as forças progressistas obtiveram importantes vitórias com a aprovação da Carta de 5 de outubro de 1988, sendo certo que, "sobretudo nos artigos referentes aos direitos sociais e individuais, a cidadania ganhava generosas formulações e proteções formais" (AARÃO REIS FILHO, 2014:165). De toda sorte, não obstante parte considerável dos constituintes classificassem a si mesmos como "progressistas", de "centro-esquerda" ou, ainda, de "centro", de modo que, "a julgar pela autodefinição política dos deputados, o Brasil seria um país sem direita" (RODRIGUES, 1987:99), eis que "assumir-se como de direita [seria] correr o risco de ser interpretado como defensor da ditadura" (LIMA, 2009:86), a força adquirida pelo "Centrão" em oposição aos rumos progressistas trilhados pela ANC indica, quando menos, para a existência de uma considerável disputa que não se limitava apenas à inclusão de determinados dispositivos normativos no texto constitucional.

Antes, o que estava em jogo era mais do que isso: cuidava-se da questão fundamental atinente à escolha de qual projeto de país seria consagrado pela Constituição, isto é, o "horizonte de expectativas" perseguido pela "Nova República” brasileira. Em outras palavras, a definição da narrativa de futuro a ser escrita para um país ávido de porvir. No caso, consoante escreve Tarcísio Costa, "malgrado o volume e os êxitos pontuais das emendas populares, o texto promulgado foi considerado bem aquém do almejado", de modo que "as inovações - expressivas nas passagens dedicadas ao meio ambiente, educação e saúde - e a plêiade de direitos assegurados aos trabalhadores, aposentados, mulheres, crianças, 
adolescentes, idosos, índios e outras minorias, não teriam situado a Carta à altura de um suposto consenso social”, tendo "a abstenção do Partido dos Trabalhadores (PT) na votação do texto constitucional evidenciado esse sentimento de frustração" (COSTA, 2013:90).

Nesse ambiente, afigura-se relevante recuperar precisa lição de Gilberto Bercovici, segundo quem, muito embora o poder constituinte do povo seja a "grande manifestação da soberania", sendo, pois, "absoluto", sofre limitações que, se não são frutos de determinada concepção jusnaturalista, encontram substrato na ordem concreta e estrutural de determinado contexto social e seu regime de historicidade específico. Dito de outra maneira, "o poder constituinte do povo é um poder absoluto, mas exercido dentro das condicionantes culturais, históricas e materiais que encontra" (BERCOVICI, 2013:316), de modo que o debate constituinte de 1987/1988 pode e deve ser encarado como uma disputa pela construção de uma narrativa situada em um presente (suspenso) marcado pela "transição" de um passado a ser enterrado (ao menos retoricamente) que se volta à construção da narrativa de futuro para a nação, por intermédio da promulgação de um novo texto constitucional; narrativa esta cuja escrita foi intensamente disputada pelos atores político-sociais que participaram do momento constitucional simbolizado pelo biênio de funcionamento da ANC.

\section{Conclusão}

A guisa de conclusão vale reproduzir a avaliação proferida, ainda em 1988, pelo então reitor da Universidade de Brasília (UnB), Cristovam Buarque, tal qual recuperadas por Leonardo Barbosa:

"A Constituinte tinha que ser o retrato das ideias que o Brasil tem de si. E estas ideias são hoje divididas, como as de um ser esquizofrênico que se sente partido e, portanto, não vê claramente. (...) Nossa Constituição de 1988 reflete perfeitamente o mundo imperfeito ao qual ela pertence. Felizmente ela saiu assim. Não poderia ser diferente. Não 'avançou' como alguns gostariam. Não 'regrediu' como outros desejariam. Não deixou claro para onde vai o país, porque nenhum de nós tem claro para onde ele deve e pode ir. Esta é a mais perfeita de nossas constituições. Ela é inacabada como o nosso país, em processo de formação social desejando ser uma nação" (apud BARBOSA, 2012:147).

Assim, em complemento ao depoimento acima transcrito, pode-se afirmar que, ao longo do momento constitucional representado pelo biênio de 1987/1988, os atores sociais atuantes na ANC procuraram, rejeitando um passado a ser olvidado, construir projetos de

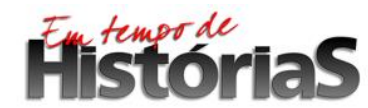


futuro a partir de um presente movediço e, nos termos empregados por Cristovam Buarque, "esquizofrênico". Nesse passo, procurou-se demonstrar que, em certa medida, a própria multiplicidade das forças políticas e dos atores sociais do Brasil de fins da década de 1980 levou a tal situação: muitos eram os "projetos" e as "promessas" para o futuro do país.

Com efeito, as disputas travadas na ribalta congressual pelos setores conservadores e progressistas - simbolizadas neste artigo pela referência à atuação do "Centrão" - mostram que, no "presente suspenso" no qual se deu o desenrolar da ANC, um país disposto a abandonar o passado autoritário (até que ponto?) pôde enxergar na elaboração da Carta Constitucional uma promessa de futuro marcada de um simbolismo ímpar. Em certa medida, uma promessa de futuro inacabada - assim como a relação deste mesmo país com seu tempo, fruto de um acerto de contas com o passado que teimamos em não realizar.

\section{Referências Bibliográficas}

AARÃO REIS FILHO, Daniel. Ditadura e democracia no Brasil: do golpe de 1964 à Constituição de 1988. Rio de Janeiro: Ed. Zahar, 2014.

ABREU, Alzira Alves de [et a.] Dicionário Histórico-Biográfico Brasileiro (Pós-1930), Vol. II. Centrão (verbete). Rio de Janeiro, FGV, CPDOC, 2001.

ARTURI, Carlos S. "O debate teórico sobre mudança de regime político: o caso brasileiro". In: Revista Brasileira de Sociologia e Política, n. 17, nov. 2011, pp. 11/31.

BARBOSA, Eduardo Ubaldo. O momento Burke: notas para a história de um Iluminismo contrarrevolucionário. Em tempo de História (v. 1), 2015, pp. 49/65.

BARBOSA, Leonardo Augusto de Andrade. História constitucional brasileira: mudança constitucional, autoritarismo e democracia no Brasil pós-1964. Brasília: Câmara dos Deputados, 2012.

BERCOVICI, Gilberto. O Poder Constituinte do povo do Brasil: um roteiro de pesquisa sobre a crise constituinte. In: Constituição e Poder Constituinte: Lua Nova - Revista de Cultura e Política n. 88 (ISSN 01026445), 2013.

CANOTILHO, J. J. Gomes. "Brancosos" e interconstitucionalidade: itinerários dos discursos sobre a historicidade constitucional. Coimbra, Ed. Almedina, 2006.

COSTA, Tarcísio. O debate constituinte: uma linguagem democrática? In: Constituição e Poder Constituinte: Lua Nova - Revista de Cultura e Política n. 88 (ISSN 0102-6445), 2013.

ELSTON, Jon. Constitutional Bootstraping in Philadelphia and Paris. In: ROSENFIELD, Michel (ed.) Constitutionalism, Identity, Difference and Legitimacy: theoretical perspectives. Burham: Duke University Press, 1994, pp. 57/83.

FREITAS, R. MOURA, S. e MEDEIROS, D. Procurando o Centrão: Direita e Esquerda na Assembléia Nacional Constituinte 1987/1988. Concurso ANPOCS - Fundação Ford: Melhores Trabalhos sobre a Constituição $\quad$ de $1988 . \quad$ Disponível em: http://scholar.google.com.br/scholar_url?url=http\%3A\%2F\%2Fwww.cebrap.org.br\%2Fv3\%2Farquivos\%2Fartig os\%2Fprocurando-o-centrao-direita-e-esquerda-na-assembleia-nacional-constituinte-1987-88-9986.pdf\&hl=ptBR\&sa=T\&oi=ggp\&ct=res\&cd=0\&ei=Q3mSV8nSGcuBmAHWlbbwDw\&scisig=AAGBfm3NKQ6Toiu8iglqZ 0SR2Rjz1n9V5g\&nossl=1\&ws=1366x675 
HARTOG, François. Regimes de historicidade: presentismo e experiências do tempo. Belo Horizonte: Ed. Autêntica, 2013.

v. 1,2013 . "Experiência do tempo: da história universal à história global?” In: história, história, n. 1,

KOSELLECK, Reinhart. Futuro Passado: contribuição à semântica dos tempos históricos. Rio de Janeiro: Ed. Contraponto, 2006, p. 322.

LASSALLE, Ferdinand. A Essência da Constituição. Porto Alegre: Ed. Freitas Bastos, 9a ed., 2014.

LIMA, Luziano Pereira Mendes de. A atuação da esquerda no processo constituinte (1986-1988). Brasília: Câmara dos Deputados, 2009.

MENCK, José Theodoro Mascarenhas. Constituinte de 1987 e a Constituição Possível. In: Ensaios sobre impactos da Constituição Federal de 1988 na sociedade brasileira (vol. I). Brasília: Câmara dos Deputados, 2008.

MONCLAIRE, Stéphane. Um processo de longo prazo (no prelo).

MUNHOZ, Sara Regina. Atuação do “Centrão” na Assembléia Nacional Constituinte de 1987/1988: dilemas e contradições. Revista Política Hoje, Vol. 20, n. 1, 2011, pp. 343/394.

WALDRON, Jeremy. Precommitment and Disagreement. In: ALEXANDER, Larry (org.) Constitutionalism: Philosophical Foundations. Cambridge: Cambridge University Press, 2001. 